\title{
Temperature management of potatoes in packaging with reusable plastic crates in the fresh produce supply chain
}

\author{
Simon Jones ${ }^{1}$, Chris Bishop ${ }^{2}$, Roy Porter ${ }^{3}$, Chaiwong Saowapa ${ }^{1,4}$ \\ ${ }^{1}$ Postharvest Unit, Writtle University College, Chelmsford, Essex, UK CM1 3RR \\ ${ }^{2}$ University of Lincoln, Holbeach Campus, Lincolnshire, UK \\ ${ }^{3}$ Chemistry Department, University of West Indies, Kingston, Jamaica \\ ${ }^{4}$ School of Agro-Industry, Mae Fah Luang University, Chiang Rai, Thailand
}

*Corresponding author: CBishop@lincoln.ac.uk

\begin{abstract}
Although initially the introduction of reusable plastic crates was because off cost savings, their speed of adoption was accelerated by environmental considerations. RPCs having a lower direct impact across a broad range of environmental parameters when compared with than display-ready containers (DRCs)., Also RPCs can have an indirect effect with lower levels of produce waste, further reducing the environment impact of using plastic crates. This paper considers the temperature management challenges with packaging formats used in the fresh produce supply chain. The different scenarios are compared of bagged and loose potatoes in RPCs and DRCs when placed in still and moving air. The temperature changes of the potato flesh showed that with the greater free area of the RPCs there is potential to warm up significantly more quickly than with DRCs. In the first three hours the flesh temperatures for loose potatoes in RPCs increased at almost three times the rate experienced in DRCs. The study found that with RPCs for the temperature rise in the first hour in air at $0.1 \mathrm{~m} / \mathrm{s}$ was fifteen times as great as in still air, but with the adoption of a single plastic film wrap of 25 micron polythene it was reducing the temperature rise by $69 \%$. The adoption of RPCs throughout the supply chain has had many advantages but these trials highlight the potential issues with temperature and quality management, However the study underline the dangers of changing packaging formats without paying due consideration to the temperature and airflow variables inherent in each packaging format.
\end{abstract}

Keywords: Packaging; potatoes; quality management; returnable plastic crates.

Abbreviations: DRCs _ display-ready containers; HaFS _ hospitality and foodservice; PFA - percentage free area; RDC _ regional distribution centre; RPCs _ reusable plastic crates.

\section{Introduction}

Traditionally the main objectives of packaging in the fresh produce supply chain have been to protect the product from its environment and to maintain produce quality (Harte and Gray, 1987), there are several additional functions including supporting efficient distribution and marketing of produce, extending shelf-life and preventing spoilage and waste of produce (Verghese et al., 2006). Increasingly packaging is required to also engage consumers via automatic identification systems and drive links to social networking and infotainment websites to develop an emotional connection with the consumer (Lindqvist et al., 2012). Retailers are the only sector in the supply chain where packaging interacts directly with the consumer, therefore deciding which products will be offered and in which format has a critical influence in the development of environmentally friendly packaging. Working with the Waste and Resources Action Programme (WRAP) to develop 'The Courtauld Commitment' (WRAP, 2011) retailers in the UK have sought to reduce the total amount of packaging used and to design for recyclability and ideally use recycled content with an increased convenience and reduction of waste with easy-open and re-close features. The retailers also within "The Courtauld Commitment" have sought to re-think product usage with refillables, concentrates and self- dispensing packaging and source from stewardship certified manufacturers and, finally, to reduce supply chain costs by introducing display-ready packaging including roll cages and RPCs. The Courtauld Commitment Phrase 3 launched in 2013 (WRAP, 2013a)) has targets to further reduce the environmental impact of household food waste, grocery products and packaging waste in the retail supply chain. The packaging target seeks to improve packaging design through the supply chain to maximise recycled content, improve recyclability and deliver product protection to reduce food waste. WRAP comments that because packaging optimisation has increased, there are now only limited opportunities to reduce it further without risking increased product wastage, with the focus now on eco-design to optimise recycled content and improve recyclability. WRAP launched the Hospitality and Food Service Agreement in 2012 covering stakeholders in the Hospitality and Foodservice (HaFS) sector with targets to reduce food and related packaging waste by $5 \%$ as well as increasing recycling rates to $70 \%$ or over by the end of 2015 (WRAP, 2013b). A UK study by Salvá et al., (2013) examined environmental issues with growers supplying the HaFS sector and found that business practices for packaging varied greatly and were affected by the suppliers' different business operations and the 
consequent demands made by customers. Several suppliers in the study reported using RPCs and were additionally working with upstream suppliers and downstream customers to promote the efficient use of packaging in the supply chain. Some suppliers reported using very little packaging for their products because they supplied to restaurants not to final consumers so the packaging was less elaborate.

A study of fresh produce supply chains in Europe by Albrecht et al., (2013), following the work of Barthel et al., (2007) and Albrecht et al., (2009), used Life Cycle Costing as part of a Life Cycle Assessment to analyse the cost implications of switching from DRCs to RPCs. The study found that the overall cost of a RPC system was $50-60 \%$ less than the cost of wooden DRCs and $65-75 \%$ less than the cost of cardboard DRCs. The cost difference became more pronounced the number of times the RPCs were re-used.

A European study by the Fraunhofer Institute, (1993) examined the environmental impacts of RPCs and DRCs and found that RPCs have less impact than DRCs when they exceed a minimum number of uses over their lifespan. A pan European study found that RPCs had less environmental impact on measures for global warming, acidification, eutrophication and photochemical ozone creation (Albrecht et al., 2013). A study by BRC, (2000) found that RPCs have less environmental impact than DRCs. A later North American study by Singh et al., (2006), following the work of Franklin Associates (2004), also found that RPCs reduce packaging waste, as well as using less materials to manufacture and generating fewer emissions than DRCs.

The use of RPCs can have a direct effect by generating a lower environmental impact than DRCs, but can also have an indirect effect in that the reduced damage to fresh produce with RPCs leads to lower levels of produce waste, further reducing the environment impact of using RPCs.

A study on Wholesale Distribution Centres by Thompson and Kader, (2001) found that RPCs reduce damage due to shipping and handling because they are stronger and more resilient than DRCs, being designed to withstand multiple reuses. A later study observes that design and use of protective packaging materials are important considerations in reducing physical damage and consequently fresh produce waste (LeBlanc and Hun, 2005).

A study in Sri Lanka found that using RPCs instead of wooden DRCs reduced losses of mangoes and avocados from $30 \%$ to $6 \%$ (Fernando, 2006). Research on mangoes and papayas in Thailand compared the incidence of damage with RPCs, other plastic containers and corrugated paper DRCs and found a reduced incidence of damage with the RPCs, especially with a single layer of produce (Chonhenchob and Singh, 2003; Chonhenchob and Singh, 2005).

Trials on the island of Mauritius with tomatoes carried out at different times of the year found that of the harvested fruit only around $25 \%$ was available for sale at the market. The authors reported reduced losses by improving handling methods, replacing deep wooden DRCs with smooth sided RPCs and additionally keeping the crop on wooden pallets in the shade whenever possible (Bishop and Ramma, 2012).

\section{Temperature Management}

The adoption of RPCs has come at the same time as an increased emphasis on temperature management in the cool chain (Bishop et al., 2002). Much of the fresh produce packed in RPCs in the retail supply chain will pass through a supermarket Regional Distribution Centre (RDC) and in many cases the air temperature of the RDC will be around $15-20{ }^{\circ} \mathrm{C}$ as a mix of products is being handled where temperature is not critical (Bishop and Haney, 2008). The authors have received verbal reports of a number of cases when produce has been rejected as too warm after a period of 4-6 hours in the RDC. The total time from packer to supermarket can be more than 18 hours including the time in the refrigerated transport. RPCs have a much higher percentage free area (PFA) at around 20\% compared with DRCs with a PFA of 3.5-5\%, allowing for a greater airflow through the RPC. The higher PFA of RPCs results in faster cooling and has been found to result in faster warming even under low air movement. A study on netted oranges found that the temperature increase in the first 4 hours was 5-6 times higher with RPCs than with DRCs and 3-4 times higher for the next 3 hours (Bishop and Hanney, 2008).

This study examines the temperature and quality management challenges with packaging formats used in the fresh produce supply chain by comparing bagged and loose dry washed potatoes in RPCs and DRCs kept in still and moving air.

\section{Results and Discussion}

\section{Loose potatoes in DRCs vs. Loose Potatoes in RPCs}

The first trial examined loose potatoes in both DRCs and RPCs and the results showed that with the greater PFA of the RPCs the produce warmed up more quickly than in cardboard cartons. In the first three hours of the trial the flesh temperatures for loose produce in RPCs increased at almost three times (2.95) the rate for loose produce in cardboard DRCs. Over the seven hour trial the produce in RPCs increased in temperature at over twice (2.02) the rate of DRCs with a maximum increase in hour two of almost three times (2.94) and a minimum in hours four and six of more than one (1.43). The results over the seven hour trial all were significant at $p=0.005$. It can be seen in figure 1 that the temperature increase of the flesh temperature reduces after hour three and this is thought to be because the temperature differential between air and flesh is reducing which reduces heat flow.

\section{Bagged Potatoes in RPCs vs. Loose Potatoes in RPCs}

This trial was carried out with bagged potatoes and unbagged potatoes in RPCs and the results show that for the first three hours there is a large difference in the rate of warming but this declined as the trial progressed. There are thought to be two reasons for this the first being that the temperature difference between the tubers and the air around them is declining which would reduce heat transfer. The second reason is that a small amount of condensation was observed on some tubers after about three hours. The increase in temperature over the seven hour trial was $9.48{ }^{\circ} \mathrm{C}$ for the un-bagged product compared to $1.52{ }^{\circ} \mathrm{C}$ for the bagged product. The results over the seven hour trial all were significant at $\mathrm{p}=0.005$.

\section{Bagged Potatoes in DRCs vs. Bagged Potatoes in RPCs}

The trial was then carried out on bagged potatoes in DRCs and RPCs and it can be seen in figure 3 that for the first three hours there is very little difference in the change of temperature between the two carton types. However there is then a big difference in the temperatures in hours four, five and six, resulting in a mean difference in flesh temperature of $1.15{ }^{\circ} \mathrm{C}$ by the end of seven hours $\left(4.70{ }^{\circ} \mathrm{C}\right.$ with RPCs as opposed to $3.55^{\circ} \mathrm{C}$ with DRCs). It is thought that this change in rate of temperature increase is because the inertia of any 


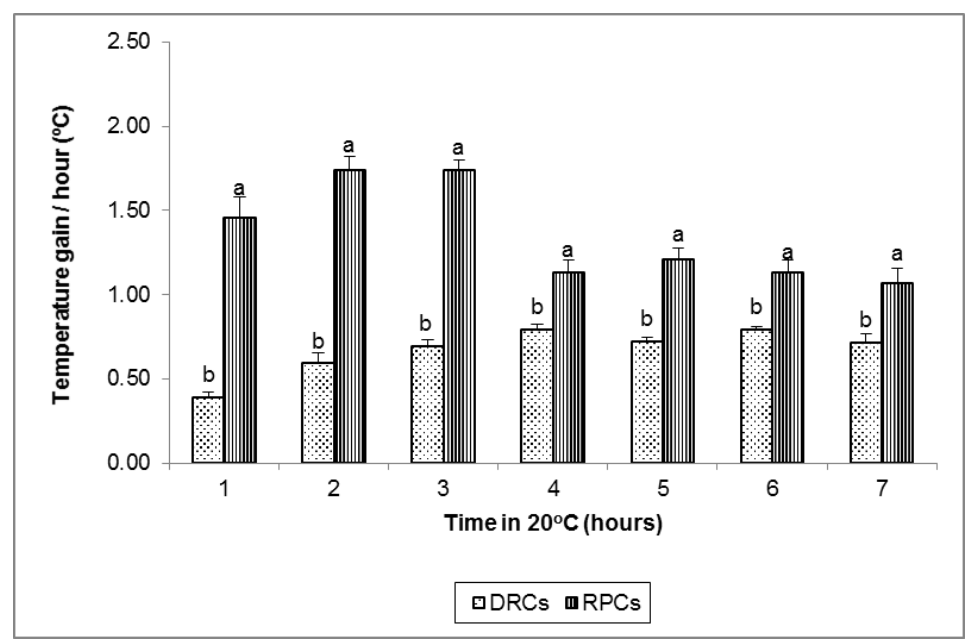

Fig 1. The temperature increase per hour in still air from an initial temperature difference of $16{ }^{\circ} \mathrm{C}$ between tubers and air for loose potatoes in DRCs and loose potatoes in RPCs.

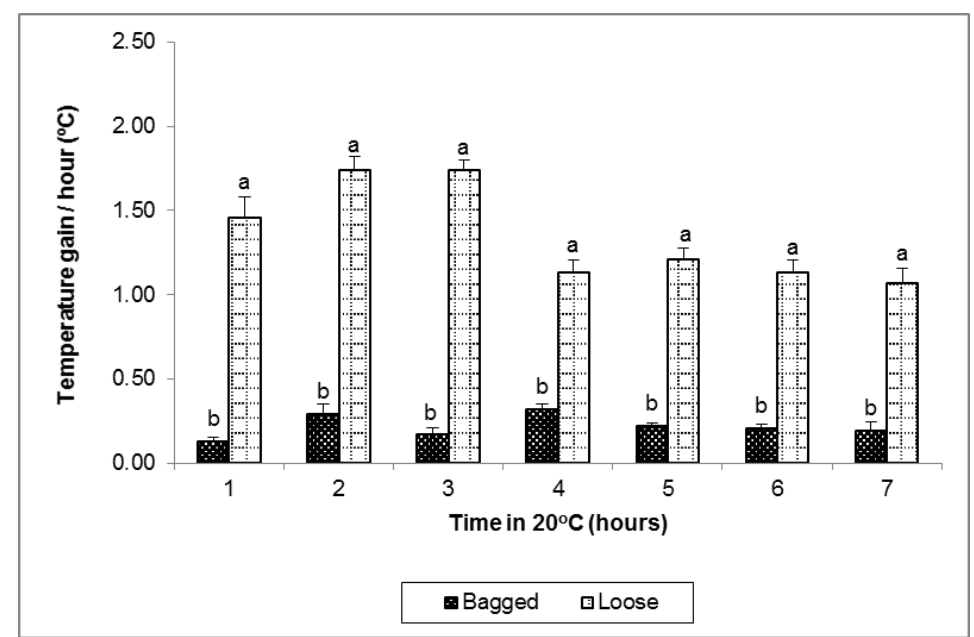

Fig 2. The temperature increase per hour in still air from an initial temperature difference of $16^{\circ} \mathrm{C}$ between tubers and air for bagged potatoes in RPCs and loose potatoes in RPCs.

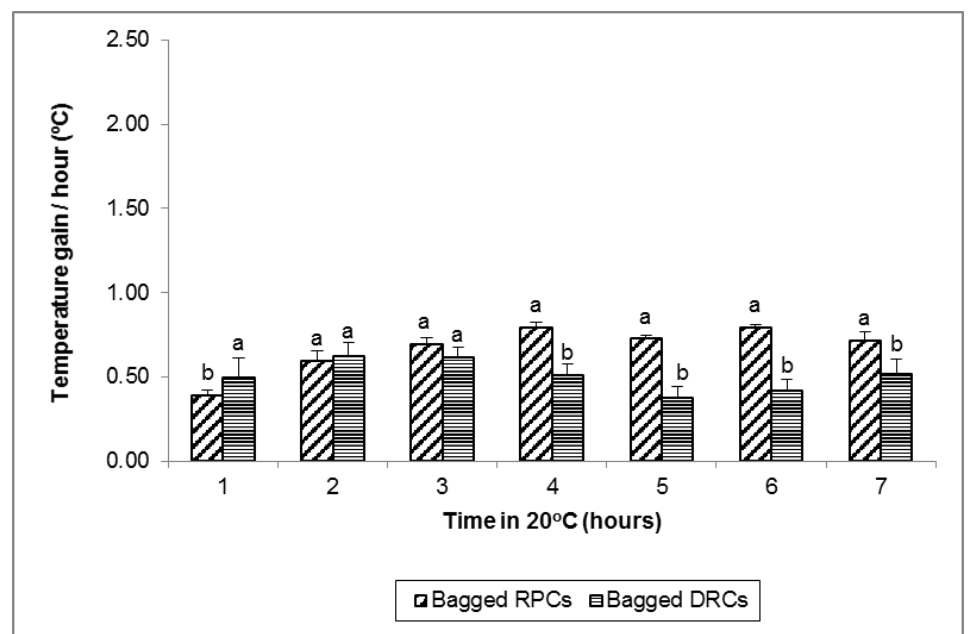

Fig 3. The temperature increase per hour in still air from an initial temperature difference of $16^{\circ} \mathrm{C}$ between tubers and air for bagged potatoes in DRCs and bagged potatoes in RPCs. 


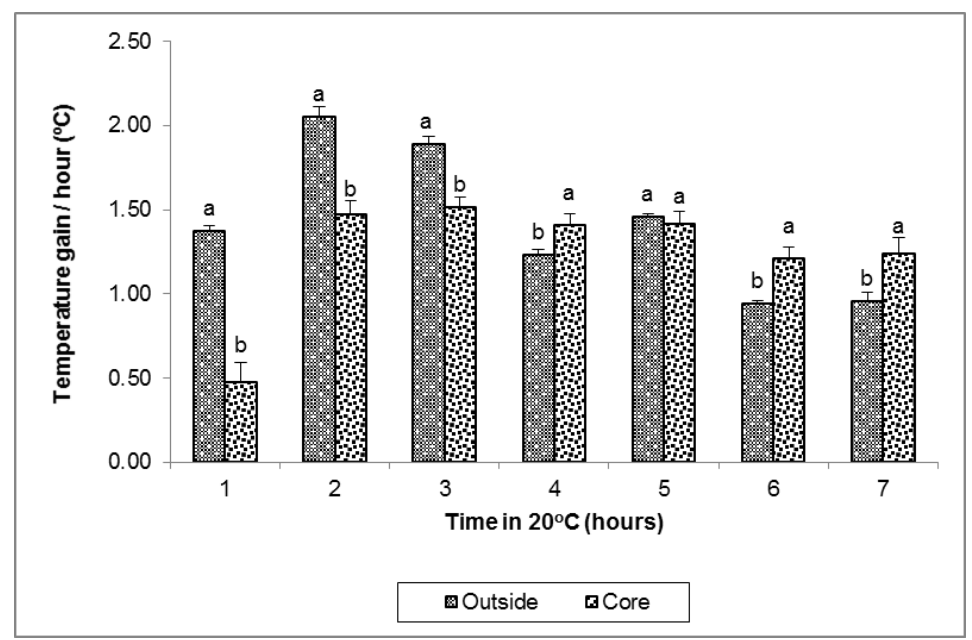

Fig 4. The temperature increase per hour in still air from an initial temperature difference of $16{ }^{\circ} \mathrm{C}$ between tubers and air for loose potatoes in RPCs at the core and at the perimeter.

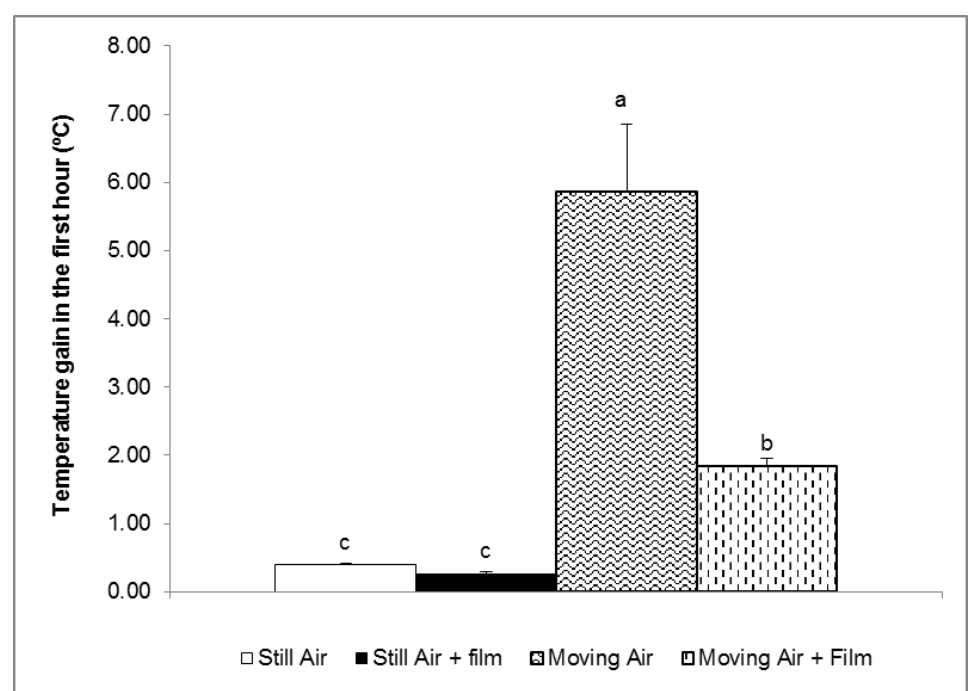

Fig 5. The temperature increase in the first hour of loose produce in RPCs in moving air with and without a plastic film wrap for an initial difference in temperature of $16{ }^{\circ} \mathrm{C}$ between tubers and air.

insulating effects of the polythene bag (in the range 25-35 $\mu$ ) had dissipated by the fourth hour. The results in hours one, four, five, six and seven were significant at $\mathrm{p}=0.005$.

\section{Temperature Differential across the Layer}

Whereas in the first two sets of trials the temperature loggers were placed in a uniform grid across the layer of crate in the $3^{\text {rd }}$ layer on the pallet, in this trial of loose potatoes three temperature loggers were placed in the outside $150 \mathrm{~mm}$ of the pallet and three placed in the central core.

The results show that in the first three hours there was a greater increase in temperature at the perimeter but subsequently there was a greater increase at the core, this is thought to be because of the greater temperature differential between the tubers and the air. The mean temperature increase over the seven hour trial was $8.74{ }^{\circ} \mathrm{C}$ at the core and $9.91{ }^{\circ} \mathrm{C}$ at the perimeter. The results in hours one, two, three, four, six and seven were significant at $\mathrm{p}=0.005$.

\section{Temperature Rise in Moving Air}

Two trials were carried out with an airflow of approximately $1.5 \mathrm{~ms}^{-1}$ created by a $600 \mathrm{~mm}$ propeller fan running at 1440 rpm. The fan was two metres and at right angles from the nearest edge of the pallet load. The potatoes were loose within the RPCs and the initial temperatures were similar to the other trials. The trial was repeated two further times with the RPC stack covered with a single layer of plastic film (approximately $18 \mu$ ). The results showed that with RPCs the temperature rise in the first hour of loose produce in moving air was almost fifteen times (14.96) as great as in still air, with the adoption of a single plastic film wrap reducing the temperature rise in the first hour in moving air by $69 \%$ as shown in figure 5 . The results in moving air were significant at $\mathrm{p}=0.005$.

\section{Materials and Methods}

\section{Plant and Packaging Material}

Potatoes ( $\mathrm{Cv}$ Cara) were used for the evaluation as they are one of the highest volume produce lines to go through the cool chain. Standard open topped cardboard and supermarket RPC of nominal $600 \times 400 \times 200 \mathrm{~mm}$ of around $4 \%$ and $20 \%$ free area respectively were used. The bagged potatoes were in bags of nominally $2.5 \mathrm{~kg}$ unless otherwise stated. Six bags were used per RPC/DRC giving a mean weight of produce of 
approximately $15.5-16.0 \mathrm{~kg}$ - for the loose potatoes the mean weight was 15.2-15.8 kg;

\section{Temperature test}

The potatoes werr kept in a cold store set at $3.5-4{ }^{\circ} \mathrm{C}$ ( approximately 90\% RH) for at least 72 hours prior to the trial and then the flesh temperatures were measured at a minimum of six locations in the same layer of the pallet $\left(3^{\text {rd }}\right.$ from the base) using Gemini "Tinytalk" external lead temperature loggers. Flesh readings were in the range 4.0-4.6 ${ }^{\circ} \mathrm{C}$. The pallet was placed in a room with still air $\left(19-21{ }^{\circ} \mathrm{C}\right.$ with an RH of $60-70 \%$ )) with $0.3 \mathrm{~m}$ or more of space around the pallet in all cases unless otherwise stated. Results are a mean of flesh temperatures in different locations for each trial. Each trial was repeated a second time using the same potatoes once initial conditions had been re-established

\section{Statistical analysis}

The first four trials were analysed by t-test with a significance level of 0.05 and the fifth trial was analysed by Duncan's Multiple-Range Test with a significance level of 0.05 .

\section{Conclusion}

The adoption of RPCs throughout the supply chain has had many advantages but these trials highlight the potential issues with temperature management particularly where there may be air movement. Although the temperature effects are less significant if the product is in plastic bags, where the produce is loose there may well be a higher level of Quality Control rejections due to high temperatures which would not have occurred with the traditional DRC packaging format. This study has highlighted the significant impact of the packaging format on the quality management of fresh produce and the danger of changing packaging formats without paying due consideration to the airflow and temperature variables inherent in each packaging format.

\section{Acknowledgements}

The authors would like to thank the Posthavest Laboratory of Writtle University College for their support.

\section{References}

Albrecht S, Beck T, Barthel LP, Fischer M, Dimming S, Baitz M (2009) The sustainability of packaging systems for fruit and vegetable transport in Europe based on life cycleanalysis - Update. University of Stuttgart, Dept. Life Cycle Engineering $(\mathrm{GaBi})$ on behalf of Stiftung Initiative Mehrweg (SIM), Germany. http://www.stiftungmehrweg.de. (Accessed 10 May 2016).

Albrecht S, Brandstetter P, Beck T, Fullana-i-Palmer P, Grönman K, Baitz M, Deimling S, Sandilands J, Deimling S, Fischer M (2013) The sustainability of packaging systems for fruit and vegetable transport in Europe. Int $\mathbf{J}$ Life Cycle Assess. 18(8):1549-1567.

Barthel LP, Albrecht S, Baitz M, Deimling S, Fullana-iPalmer P, Gazulla C, Balazs, S, Des Abbayes C (2007) The sustainability of packaging systems for fruit and vegetable transport in Europe based on life cycle-analysis. University of Stuttgart, Dept. Life Cycle Engineering $(\mathrm{GaBi})$ on behalf of Stiftung Initiative Mehrweg (SIM), Germany.
http://www.plasticsconverters.eu/uploads/Final-ReportEnglish-070226.pdf (Accessed 10 May 2016).

Bishop CFH, Hanney SJ (2008) Environmentally compatible packaging of fresh agricultural and horticultural produce. In: Chiellini E (ed.) Environmentally compatible food packaging, Woodhead, Cambridge, UK, 2008.

Bishop CFH, Ramma I (2012) Postharvest loss reduction of 'MST32/1'cooking tomatoes produced by small farmers in Mauritius. In: Cantwell MI and Almeida DPF (eds.) Proceedings of XXVIIIth IHC - IS on postharvest technology in the global market, Acta Hort. 934, ISHS 2012.

Bishop CFH, Wainwright H, Pailes P (2002) The cool chain: an integrated temperature management system for fresh produce. In: Dris R, Niskanen R and Jain SM (eds.) Crop management and postharvest handling of horticultural products, Science Publishers, Enfield, New Hampshire, USA, 2002.

BRC: Business Research and Consulting (2000) Feasibility of reusable plastic containers for shipping and displaying produce. Alameda County Source Reduction and Recycling Board, California, USA.

Chonhenchob V, Singh SP (2003) A comparison of corrugated boxes and reusable plastic containers for mango distribution. Pack Technol Sci. 16(6):231-237. DOI:10.1002/pts.630.

Chonhenchob V, Singh SP (2005) Packaging performance comparison for distribution and export of papaya fruit. Pack Technol Science. 18(3):125-131.

Fernando MD (2006) Country paper - Sri Lanka. In Proceedings of seminar on post-harvest management of fruit and vegetables in the Asia-Pacific region, Asian Productivity Organization (Tokyo) and United Nations Food and Agriculture Organization (Rome), 2006, 264-275. http://www.apo-tokyo.org/00e-books/AG-

18_PostHarvest/AG-18_PostHarvest.pdf (Accessed 10 May 2016).

Franklin Associates (2004) Life cycle inventory of reusable plastic containers and display-ready corrugated containers used for fresh produce applications. Reusable Pallet and Container Coalition (RRPC), Kansas, USA. http://www.usereusables.com/downloads/LCI\%20Preface\% 20\&\%20Executive\%20Summary.pdf (Accessed 10 May 2016).

Fraunhofer Institute (1993) Ecological comparison of a disposable and a returnable transportation packaging system. Fraunhofer Institute, Dortmund, Germany.

Harte BR, Gray JI (1987) The influence of packaging on product quality. In: Gray JI, Harte BR, Miltz J (eds.) Food product-package compatibility, Technomic Publishing, Lancaster, USA.

LeBlanc D, Hui KP (2005) Land transportation of fresh fruits and vegetables: An update. Stewart Postharvest Review, 1(4):1-7.

Lindqvist U, Federley M, Hakola L, Laukkanen M, Mensonen A, Viljakainen A (2012) Consumer demand for information accessible through automatic identification. Pack Technol Sci. 25:1-6.

Salvá M, Jones S, Marshall RJ, Bishop CFH (2013) An audit tool for environmental measurement in the UK food sector. Int J Food Sci Technol. 48(7): 1509-1518.

Singh SP, Chonhenchob V, Singh J (2006) Life cycle inventory and analysis of re-usable plastic containers and display-ready corrugated containers used for packaging fresh fruits and vegetables. Pack Technol Sci. 19(5):279293. 
Thompson J, Kader AA (2001) Wholesale distribution center storage. http://ca-refrigeration.com/hb66/015wholesale.pdf (Accessed 10 May 2016).

Verghese K, Horne R, Fitzpatrick L, Jordan RP (2006) PIQET - A packaging decision support tool. In: Proceedings of the 5th Australian Conference on Life Cycle Assessment, Melbourne, Australia, 22-24 November 2006.

WRAP: (2011) The Courtauld Commitment Phase 2 First Year Progress Report. http://www.wrap.org.uk/sites/files/wrap/CC2_First\%20Yea r\%20Progress\%20Report\%2C\%2005\%20Dec\%2011\%20fi nal.pdf (Accessed 10 May 2016).
WRAP (2013a) The Courtauld Commitment Phase 3. http://www.wrap.org.uk/content/courtauld-commitment-3 (Accessed 10 May 2016).

WRAP (2013b) The Hospitality and Food Service Agreement. http://www.wrap.org.uk/content/hospitalityand-food-service-agreement-3 (Accessed 10 May 2016). 